\title{
Competing Causes of Death in 138 Patients with Loco-Regionally Advanced Head and Neck Cancer Treated with Multi-Modality Treatment
}

\author{
D. Dequanter*, M. Shahla, C. Aubert, Y. Deniz, P. Lothaire \\ Department of Head and Neck Surgery, CHU Charleroi, Montigny le Tilleul, Belgium \\ Email: ${ }^{*}$ didier.dequanter@pandora.be
}

Received 23 March 2015; accepted 15 May 2015; published 18 May 2015

Copyright (C) 2015 by authors and Scientific Research Publishing Inc.

This work is licensed under the Creative Commons Attribution International License (CC BY).

http://creativecommons.org/licenses/by/4.0/

(c) (i) Open Access

\begin{abstract}
Introduction: The goal of this study was to analyze the causes of death in patients with loco-regionally advanced squamous cell carcinoma (HNSCC) of the head and neck treated with multimodality treatment. Materiel: The mortality records of 138 advanced head and neck patients treated in our department with surgery and adjuvant (chemo) radiotherapy from 2007 to 2013 were collected and reviewed in this study. Results: From May 2007 to January 2013, 138 patients were followed up with a median follow-up duration of 25 months. The 5-year overall survival (OS), disease-free survival (DFS) were $45 \%$, and $56.1 \%$, respectively. A total of 39 patients $(28 \%)$ died during the follow-up period. Clearly, in this population, loco-regional relapse accounted for one of the most cause of death but acute and late or chronic treatment-associated causes leading to death occurred in almost $8 \%$ of the patients. Furthermore, the risk of death from head and neck squamous cell carcinoma (HNSCC) was greater in patients with hypopharynx cancer. Univariate analysis indicated that patients with $\mathrm{N} 2 \mathrm{~b}$ disease and above and vascular tumor embolism had a lower overall survival $(p=0.001$ and $p=0.007$ respectively). The multivariate analysis showed that $\mathrm{N} 2 \mathrm{~b}$ disease and above was an independent prognostic factor for poorer loco-regional control $(p=$ 0.001). Conclusions: Patients with locally advanced head and neck cancer treated with surgery and adjuvant (chemo) radiotherapy are potentially curable but face significant risks of mortality from causes other than disease progression.
\end{abstract}

\section{Keywords}

Mortality in Treated Head and Neck Patients, Advanced Head and Neck Disease, Surgical Resection,

"Corresponding author.

How to cite this paper: Dequanter, D., Shahla, M., Aubert, C., Deniz, Y. and Lothaire, P. (2015) Competing Causes of Death in 138 Patients with Loco-Regionally Advanced Head and Neck Cancer Treated with Multi-Modality Treatment. Journal of Cancer Therapy, 6, 423-427. http://dx.doi.org/10.4236/jct.2015.65045 


\section{(Chemo) Radiotherapy}

\section{Introduction}

Despite remarkable advances in the care of patients with advanced head and neck cancer over the past several decades [1] [2], including a growing awareness of therapeutic complications and attention to quality of life, little is known about the causes of mortality in this population. In addition to the malignancy itself, acute and late chronic treatment associated causes, second primary cancers, intercurrent disease and psychosocial factors are all responsible for patient morbidity and mortality.

The goal of this study was to analyze the causes of death in patients with loco-regionally advanced squamous cell carcinoma (HNSCC) of the head and neck, in the hope of guiding future interventions to improve the longevity and quality of life with this cancer.

\section{Materiel}

The mortality records of 138 consecutive stage IV head and neck patients treated in our department with surgery and adjuvant (chemo) radiotherapy from 2007 to 2013 were collected and reviewed in this study (Table 1). Survival was calculated with the Kaplan-Meier method. A Cox proportional hazards regression model was applied to access the correlation between tumor location, neck metastasis (size and number), anatomopathological parameters such as vascular or perineural invasion and loco-regional control and overall survival.

\section{Results}

Up to January 2013, 138 patients were followed up with a median follow-up duration of 25 months. The 5-year overall survival (OS), disease-free survival (DFS) were $45 \%$ and $56.1 \%$, respectively. A total of 39 patients (28\%) died during the follow-up period among these 39 patients, 14 patients $(10 \%)$ presented with treatment failure. 10 patients had loco-regional relapse, 2 patients had distant metastases and 2 patients presented with both loco-regional relapse and distant relapses.

Complications of treatment leading to death occurred in 11 patients (8\%).

The emergence of second primary malignancies was the third cause of death (in 7 patients (5\%)).

The mortality rate after surgery was $2.7 \%$. The study shows the difficulty of establishing the cause of death of 3 patients (2.1\%) who have undergone a heavy surgical operation. Two patients $(2.1 \%)$ with potentially curable disease refused part or all cancer treatment.

The risk of death from head and neck squamous cell carcinomas (HNSCC) was greater in patients with hypopharynx cancer. Univariate analysis indicated that patients with invaded lymph nodes (N2b disease and above) and vascular tumor embolism had a lower overall survival ( $\mathrm{p}=0.001$ and $\mathrm{p}=0.007$ respectively). The multivariate analysis showed that invaded lymph nodes (N2b disease and above) was an independent prognostic factor for poorer loco-regional control $(\mathrm{p}=0.001)$.

\section{Discussion}

In our study, loco-regional recurrence was one of the most causes of death. Irrespective of the primary treatment used, the problem of local and regional recurrence strongly depends on the stage of disease. For low volume, early stage tumors, a high rate of disease control is anticipated, and in case of local failure, there is often opportunity for salvage resection with reasonable prospects for cure and attaining a satisfactory functional outcome.

Table 1. 5 year disease free survival and overall survival.

\begin{tabular}{cccc}
\hline Stage & N & DFS (\%) & OS (\%) \\
\hline IV & 138 & 45 & 56.1 \\
\hline
\end{tabular}

DFS 5 year disease free survival, OS overall survival. 
Conversely, in advanced stage disease, local and regional failures are significant predictors of survival, and election of the most suitable treatment for individual patients is more elaborate. In our study, all the patients presented a stage IV head and neck tumor at diagnosis. 14 patients (10\%) presented with treatment failure. 10 patients had loco-regional relapse, 2 patients had distant metastases and 2 patients presented with both loco-regional relapse and distant relapses.

In their series, Qian et al. [3] reviewed the clinical data of 125 postoperative patients. Among the 43 patients presented with treatment failure, 13 patients had loco-regional relapse, 20 patients had distant metastasis and 10 patients presented with both loco-regional and distant relapses.

In the literature data, perioperative mortality averaged 5.2\% (range 3\% - 18\%) [1] [2] [4] [5]. In our series, the perioperative mortality was $2.1 \%$ [4] [5].

Conversely, the mortality due adjuvant (chemo) radiotherapy was high in our series (8\%). As known, the most important risk factors for head and neck cancer are alcohol, tobacco consumption and associated comorbidities [6]. Given aggressive and multidisciplinary, curative-intent approaches for these patients with advanced head and neck cancer and the treatment-associated mortality may occur from therapy - related causes [7]. In those patients with associated comorbidities, the risk of dying during the follow-up period is significantly increased [7].

In our series, mortality was, mostly, due to aspiration and pneumonia resulting a septic shock. Stroke related to atherosclerosis of the carotid artery and liver and renal function deterioration were other causes of death. Furthermore, patient morbidity was high. The evaluation of acute toxicity revealed that $50 \%$ of the patients had grade II mucositis, $25 \%$ grade III mucositis, $2.5 \%$ grade IV mucositis. $50 \%$ of the patients had grade I skin reactions, $65 \%$ of the patients had grade I thrombocytopenia, and $24 \%$ of the patients had grade I anaemia.

Second primary cancer is a fairly common event in patients with advanced head and neck cancer often related to lifestyle choices of these patients and the "field cancerization" hypothesis [8] or the more recently proposed field tumor concept [9].

Patients with head and neck squamous cell cancer are at high risk of developing second primary lung cancer [10]-[12]. In the series published by Milano et al. [13], among 61,883 patients with head and neck squamous cell carcinoma (HNSCC) from the Surveillance, Epidemiology and End Results (SEER)) database, 4522 patients developed second primary lung cancer (any histology). The risk of second primary lung cancer after HNSCC was $5.8 \%$ (5\% in our series) at 5 years. From the cox regression, significantly adverse risk factors for second lung primary cancer included: regional versus localized HNSCC stage (hazard ratio $=1.16$ ), hypopharyngeal or supraglottic laryngeal site $(\mathrm{HR}=1.26)$, increased age $(\mathrm{HR}=1.26 /$ decade), black race $(\mathrm{HR}=1.27)$, and male sex $(\mathrm{HR}=1.26)$.

Our study shows the difficulty of establishing the cause of death of 3 patients (2.1\%) who have undergo a heavy surgical operation. Sudden death is a rare event after major head and neck surgery and occurs mainly during the first three postoperative days [14]. Alcoholism and perioperative hypotension seems to be two predictive factors for cardiac complications and sudden death [15]. The authors reported that 11 of the 12 unexplained deaths occurred during the first 3 postoperative days with a mortality incidence of $0.5 \%$. Although the mechanisms of sudden death remain unclear, careful follow-up of these patients during the early postoperative days should be performed to reduce the mortality risk by shortening the delay of care.

At least, all the clinicians involved in the care of patients with head and neck cancer have encountered patients with potentially curable disease who refuse part of all cancer treatment. Reasons for treatment refusal may be due to psychiatric illness, substance abuse, anxiety, inadequate social support, or for some, a conscious decision to forgo curative-intent therapy. In our series, two patients refused part of all cancer treatment.

In general, in order to investigate the treatment outcome of loco-regionally advanced squamous cell carcinoma of the head and neck after been treated with multi-modality approach, Baxi et al. [16] identified 35,958 three-year survivors of HNSCC with a median age at diagnosis of 60 years and a median follow-up of 7.7 years. There were 13,120 deaths during the study period. Death from any cause at 5 and 10 years was $15.4 \%$ and $41 \%$, respectively. The risk of death was greater in patients with nasopharynx or hypopharynx cancer and in patients with locally advanced disease. Second primary malignancy was the leading cause of non-HNSCC death, in their series.

Qian et al. [3] reviewed the clinical data of 125 postoperative patients. The 3-year overall survival, diseasefree survival, loco-regional control, distant metastasis-free survival were $69.7 \%, 56.1 \%, 80.8 \%$, and $73.1 \%$, respectively. In their series, distant metastasis accounted for the predominant cause of death. In our series, locoregional failure was the predominant cause of death. In our population, the risk of death was greater in patients 
with hypopharyngeal cancer.

After multivariate analysis, they found that non-radical surgery was an independent prognostic factor for overall survival. Larger size of invaded lymph nodes was an independent prognostic factor for poorer loco-regional control; higher $\mathrm{N}$ stage (N2b and above) or $\mathrm{T} 4$ stage and vascular tumor thrombi were independent prognostic factors for poorer distant metastasis-free survival. In our series, the same prognostic factors that influenced overall survival and loco-regional control were observed. Patients with invaded lymph nodes (N2b disease and above) and vascular tumor embolism had a lower overall survival ( $p=0.001$ and $p=0.007$ respectively). The multivariate analysis showed that invaded lymph nodes (N2b disease and above) was an independent prognostic factor for poorer loco-regional control $(p=0.001)$ [17].

\section{Conclusions}

Patients with locally advanced head and neck cancer treated with surgery and concurrent chemoradiotherapy are potentially curable but face significant risks of mortality from causes other than disease progression. Currently, complications of therapy are responsible for a considerable part of the causes of death in these patients. Surgery, intercurrent diseases, metachronous second primary tumors are the other risk factors of death in patients with locally advanced head and neck disease. The risk of death was greater in patients with hypopharynx cancer and in patients with locally advanced disease N2b disease and above).

The authors declare that there is no conflict of interests regarding the publication of the article.

\section{References}

[1] Ferlito, A., Haigentz, M., Bradley, P.J., Suarez, C., Strojan, P., Wolf, G.T., Olsen, K.D., Mendenhall, W.M., Mondin, V., Rodrigo, J.P., Boedeker, C.C., Hamoir, M., Hartl, D.M., Hunt, J.L., Devaney, K.O., Thompson, L.D.R., Rinaldo, A. and Takes, R.P. (2014) Causes of Death of Patients with Laryngeal Cancer. European Archives of Oto-Rhino-Laryngology, 271, 425-434. http://dx.doi.org/10.1007/s00405-013-2478-0

[2] Goodwin, W.J. (2000) Salvage Surgery for Patients with Recurrent Squamous Cell Carcinoma of the Upper Aerodigestive Tract: When Do the Ends Justify the Means. Laryngoscope, 93, 1-18. http://dx.doi.org/10.1097/00005537-200003001-00001

[3] Qian, W., Zhu, G., Ji, Q., Guo, Y., Wang, Y. and Wang, Y. (2014) Outcome and Prognostic Factors of 125 Loco-Regionally Advanced Head and Neck Squamous Cell Carcinoma Treated with Multi-Modality Treatment. Zhonghua Zhong Liu Za Zhi, 36, 217-222.

[4] Schultz, P., Chambres, O., Wiorowski, M., Hemar, P. and Debry, C. (2005) Perioperative Mortality in Oncologic Head And Neck Surgery. Journal of Otolaryngology, 34, 160-165. http://dx.doi.org/10.2310/7070.2005.00160

[5] Penel, N., Amela, E.Y., Mallet, Y., Lefebvre, D., Clisant, S., Kara, A., Neu, J.C., Everard, F. and Lefebvre, J.L. (2007) A Simple Predictive Model for Postoperative Mortality after Head and Neck Cancer Surgery with Opening Mucosa. Oral Oncology, 43, 174-180. http://dx.doi.org/10.1016/j.oraloncology.2006.02.003

[6] Doll, R., Peto, R., Boreham, J. and Sutherland, I. (2012) Mortality in Relation to Smoking: 50 Years' Observations on Male British Doctors. British Medical Journal, 328, 1519. http://dx.doi.org/10.1136/bmj.38142.554479.AE

[7] Carado, S., Moras, F., Pinto, G.J., Bhat, M., Hegde, S., Sattian, B. and Luis, N.A. (2014) Role of Concomitant Chemoradiation in Locally Advanced Head and Neck Cancers. Asian Pacific Journal of Cancer Prevention, 15, 41474152. http://dx.doi.org/10.7314/APJCP.2014.15.10.4147

[8] Slaughter, D.P., Soutwick, H.W. and Smejkal, W. (1953) Field Cancerization in Oral Stratified Squamous Epithelium; Clinical Implications of Multicentric Origin. Cancer, 6, 963-968. http://dx.doi.org/10.7314/APJCP.2014.15.10.4147

[9] Braakhuis, B.J., Tabor, M.P., Kummer, J.A., Leemans, C.R. and Brakenhoof, R.H. (2003) A Genetic Expalanation of Slaughter's Concept of Field Cancerization: Evidence and Clinical Implications. Cancer Research, 63, 1727-1730.

[10] De Bree, R., Haigentz, M. and Silver, C.E. (2012) Distant Metastases from Head and Neck Squamous Cell Carcinoma. Part I. Basic aspects. Oral Oncology, 48, 780-786. http://dx.doi.org/10.1016/j.oraloncology.2012.03.014

[11] Erkal, H.S., Mendenhall, W.M., Amdur, R.J., Villaret, D.B. and Stringer, S.P. (2001) Synchronous and Metachronous Squamous Cell Carcinomas of the Head and Neck Mucosal Sites. Journal of Clinical Oncology, 19, 1358-1362.

[12] Coca-Pelaz, A., Rodrigo, J.P. and Suarez, C. (2012) Clinicopathologic Analysis and Predictive Factors for Distant Metastases in Patients with Head and Neck Squamous Cell Carcinomas. Head \& Neck, 34, 771-775. http://dx.doi.org/10.1002/hed.21804

[13] Milano, M.T., Peterson, C.R., Zhang, H., Singh, D.P. and Chen, Y. (2012) Second Primary Lung Cancer after Head and Neck Squamous Cell Cancer: Population-Based Study of Risk Factors. Head \& Neck, 34, 1782-1788. 
http://dx.doi.org/10.1002/hed.22006

[14] Gueret, G., Bourgain, J.L. and Luboinski, B. (2006) Sudden Death after Major Head and Neck Surgery. Current Opinion in Otolaryngology \& Head and Neck Surgery, 14, 89-94. http://dx.doi.org/10.1097/01.moo.0000193171.31580.a3

[15] Gueret, G., Cosset, M.F., McGee, K., Luboinski, F.B. and Bourgain, J.L. (2002) Suddent Death after Neck Dissection for Cancer. Annals of Otology, Rhinology \& Laryngology, 111, 115-119. http://dx.doi.org/10.1177/000348940211100202

[16] Baxi, S.S., Pinheiro, L.C., Patil, S.M., Pfister, D.G., Oeffinger, K.C. and Elkin, E.B. (2014) Causes of Death in LongTerm Survivors of Head and Neck Cancer. Cancer, 120, 1507-1513. http://dx.doi.org/10.1002/cncr.28588

[17] Argiris, A., Brockstein, B.E., Haraf, D.J., Stenson, K.M., Mittal, B.B., Kies, M.S., Rosen, F.R., Jovanovic, B. and Vokes, E.E. (2004) Competing Cause of Death and Second Primary Tumors in Patients with Loco-Regionally Advanced Head and Neck Cancer Treated with Chemoradiotherapy. Clinical Cancer Research, 10, 1956-1962.

http://dx.doi.org/10.1158/1078-0432.CCR-03-1077 